\title{
Just relax and concentrate on your breathing
}

\author{
Olivia Fulton questions the value of telling people to focus on breathing during an asthma attack. \\ For series information contact Rosamund Snow, patient editor, rsnow@bmj.com
}

\section{Olivia Fulton}

"Just relax and concentrate on your breathing" is a comment that is heard by almost all patients attending an emergency department with an exacerbation of acute asthma. It's meant to reassure the patient but has exactly the opposite effect.

I have severe asthma and often have to attend my local emergency department with acute attacks. These attacks leave me struggling to breathe; sitting up is difficult and speaking almost impossible. Doctors' and nurses' initial instinct is to offer support, and naturally because of how I look their advice is to sit back, relax, and don't talk.

I always try to talk, however; and having spoken to other people with asthma they do too. Concentrating on breathing induces a sense of panic because you can't do it and fear for what will happen if this is not resolved. By talking you are concentrating on something else. Your speech may not be great, and speaking will look like a huge effort, but the effort of talking takes away the fear of not being able to breathe. This can help people having an asthma attack from falling into a vicious cycle where over-focusing on breathing ends up making them hyperventilate.

\section{Ask what works}

In the initial stages of an attack, when I'm in the emergency department, the doctors need to know everything about me as a patient. Patients with long term conditions, especially those with severe and uncontrolled asthma, often have a lot of useful information about what works and what doesn't. I often overhear doctors talking at the end of the trolley, speculating about the best course of treatment. I sit there willing them to ask me about my asthma and treatment but know they don't want to force me to talk, as from the outside it appears so difficult.

Even if it takes 5-10 minutes to complete a sentence, having someone take the time to listen is almost as much a relief as intravenous magnesium or aminophylline might be. You are reassured that the important people know the information you need them to know.

\section{Offer pen and paper}

Do ask us if we have a care plan or what our usual treatment would be. Offer a pen and paper if talking is too difficult. Patients are far more interested in the care they receive, and feel more confident, when doctors and nurses take the time to include them in decisions.

When struggling to breathe different patients adopt different positions. I like to sit as upright as possible or lean over, bracing myself with my arms on my knees. As a doctor you want to help patients into the best position for them but you also need to examine them. Naturally "lie back and relax" is what comes to mind. In fact, lying back will often make someone who has difficulty breathing feel the weight of their chest even more. Asking patients to find a comfortable position themselves will mean they are not fighting with you to get out of a position they don't want to be in. This may seem trivial but a comfortable patient is a lot easier to manage than an uncomfortable one.

I am in a fortunate position that the hospital I attend has developed an anticipatory care plan for patients with chronic conditions or complex needs. ${ }^{1}$ This can be accessed as soon as I am admitted to the hospital. Since this has been developed and accessed by the emergency medical staff my experience in the emergency department has been so much better. The doctors and nurses know what they need to know about me. I don't get agitated, willing them to ask me about my condition and treatment. I can relax knowing that I will get the treatment that works for me, rather than doctors speculating about what may or may not work, which increases my anxiety and escalates my asthma attack.

Competing interests: I have read and understood BMJ policy on declaration of interests and declare the following interests: none.

1 Scottish Government. Anticipatory care planning: frequently asked questions. www.gov. scot/Publications/2010/04/13104128/1.

Cite this as: BMJ 2015;351:h6185

๑ BMJ Publishing Group Ltd 2015 


\section{What you should know}

- Avoid saying "just concentrate on your breathing, don't talk." Although this statement is intended to reassure, it can have the opposite effect because patients may then focus on their inability to breathe and become even more frightened

- Ask patients what position they find most comfortable

- Take time to ask patients about their usual treatment and if they have a care plan. Offer a pen and paper if talking is too difficult 